\title{
The Functional Interdependence of Wind Instrumentalists' Embouchure and Their Craniofacial Features
}

\author{
https://doi.org/10.3991/ijoe.v15i13.10961 \\ Miguel Pais Clemente ${ }^{(凶)}$, José Manuel Amarante, André Moreira, \\ Afonso Pinhão Ferreira, Ricardo Vardasca, Joaquim Mendes \\ University of Porto, Porto, Portugal \\ miguelpaisclemente@hotmail.com
}

\begin{abstract}
The criteria of performing a correct embouchure can differ according to particular craniofacial features. Different teaching techniques can also lead to specific patterns of a musician embouchure, where playing in a relaxed position is one of the major indications. In order to understand if there is a "perfect embouchure", several techniques were used on the analysis of the embouchure of three different wind instrumentalists. Force sensing resistors were applied to the mouthpiece of a clarinet, infrared thermography was performed to a brass player, while a bassoon player underwent two lateral cephalograms. The examinations techniques were chosen to take advantage of the possible information that could be taken from each musician, on addition to the evidence of the intra-oral exam. The force analysis showed that the clarinetist had an asymmetrical force distribution among the two central incisors. The infrared thermography showed that the tuba player had thermal asymmetry at the region correspondent to the masseters muscles possibly related to the teeth position. The lateral cephalograms showed a $10^{\circ}$ posterior rotation of the mandible during the embouchure of the bassoon player. Therefore, understanding the anatomical limitations of the orofacial region, which may lead to an asymmetrical embouchure, is fundamental to analyze and treat a wind instrumentalist within a dental appointment.
\end{abstract}

Keywords-Embouchure, infrared thermography, lateral teleradiography force sensing resistor, wind instrumentalists

\section{$1 \quad$ Introduction}

A wind instrumentalist learns how to play its instrument since a young age of 7-8 years old. Then, by the age of 10 to 12 years he/she has to decide which will be the instrument to perform during the entire life. While music student in a school, conservatory of music university, the wind instrumentalist learns respiratory techniques and how to hold the instrument, how to keep his/her back on an upward position, and how to perform a centered embouchure in order to play the most comfortable as possible. 
At this point, it can be asked what is a "centered embouchure". Are the upper central incisors a reference for the single reed instrument player? Or the junction of the upper and lower lip for the brass player? Which reference point should be considered for the double reed player in order to have a centered embouchure? Will it be the upper lip that is retruded and folded back over the upper central incisors, or the lower lip which is also retruded over the lower incisors? What is the criteria for performing a correct embouchure technique? Are the actual musical teachers aware that there are specific craniofacial features that make a centered embouchure for a clarinet player different from a tuba player? This article intends to highlight the specificities involved in the embouchure of wind instrumentalists in order to clarify what is a perfect embouchure. For this purpose, three different techniques were used - Force Sensing Resistor (FSR), Infrared Thermal imaging (IRT) and lateral cephalograms (LC), respectively to a single reed instrument player, a brass player and a double reed instrument player.

The dentistry and performing arts community have a lot to gain with an interdisciplinary approach of using techniques and sensors common in engineering field like IRT and FSR. By working together, it makes easier to understand the underplaying mechanism of producing a musical piece, sealing the lips around the mouthpiece, positioning the tongue and mandible and obtain the different tones (high, medium and low). Lateral cephalograms can also help to understand, visualize and quantify the mechanisms involved during the embouchure procedure, leading eventually to the perfect embouchure.

Infrared thermal imaging (IRT) is a non-invasive and non-ionizing medical imaging modality that allows to map the skin temperature distribution of an area, which is related to the underlining physiology $[1,2]$. IRT has been successfully applied in different clinical conditions that can be monitored in different regions of the body. In terms of the masticatory and functional orofacial complex structures, the application of IRT is mainly focused in research, although this technique can also be easily implemented in daily clinical routine. Haddad et al. used the thermal imaging as a complementary diagnosis of myogenous TMD [3]. Functional IRT was able to discriminate healthy subjects from patients affected with myofascial pain at the regions corresponding to the masseter, sternocleidomastoid, cervical and upper trapezius muscles [4]. The use of IRT to assess the masticatory mechanism during function is a promising tool to obtain objective data from temporomandibular joint (TMJ) patients and may act as a useful indicator of the moment to stop the treatment on asymptomatic patients [5]. The thermal imaging showed to be a valuable complementary diagnostic method for mild to medium TMJ disorders [6].

The aim of this paper is to demonstrate the usefulness of each technique as a complementary tool that can be used in dentistry to analyze wind instrumentalists and their embouchure. 


\section{Materials and Methods}

\subsection{Sample}

The sample of this study consisted of three wind instrumentalists, a clarinetist, a brass and a bassoon player, with a common problem: pain on the masticatory muscles, in particular the masseter muscle. From a sample of 20 wind instrumentalists, three were chosen because they showed two extreme malocclusions, in the case of the single and double reed woodwind player; while the brass player presented a tooth rotation of a central incisor with direct implications on the embouchure mechanism. The sample for the present investigation was screened from the Orchestra Sinfónica do Porto, Casa da Música, and students from the Master of Science degree in Music and Performing arts (Superior School of Music and Performing Arts of Porto - ESMAE). The inclusion criteria were: to be adults ( $>18$ years old), playing their musical instrument for more than ten years, and should have not yet been submitted to an orthodontic treatment (nor any history of maxillofacial surgery, nor mandibular injuries).

These musicians were subject to a meticulous examination in order to understand anatomical and physiological conditioning factors. In order to analyze the underlying mechanism of their embouchure, intra-oral photographs were performed to visualize the occlusion, the possibility of existing tooth crowding, or any other characteristic that could be directly linked to the position adopted by the respective mouthpiece inside the oral cavity.

\subsection{Experimental set-up}

The exhaustive clinical examination, intra-oral photographs and the clinical history were complemented by the results of the exam technique performed to each wind instrument player; the FSR sensor was applied to the clarinet mouthpiece, the IRT was done to the brass player, while the bassoon player underwent a lateral cephalogram.

Clarinet Player: The clarinet player, as shown in Fig. 1a, presents a malocclusion with an anterior open bite, and therefore FSR sensors were placed on the upper surface of the mouthpiece in order to quantify the pressure applied to the upper central incisors during the embouchure (Fig. $1 \mathrm{~b}$ and $1 \mathrm{c}$ ).

The FRS sensors (FlexiForce model A201-1 lb/sqi) were previously integrated in an electrical circuit according the recommendations of the maker (Tekscan, Boston, MA, USA) and connected to a four-channel Universal Analog Input Module 9219, mounted in the NI-USB 9162 Carrier (National Instruments, Austin, TX, USA). Sensor characterization was made through polynomial regression using four different masses $(100 \mathrm{~g}, 250 \mathrm{~g}, 500 \mathrm{~g}$ and $1000 \mathrm{~g})$. The output signal was displayed and recorded with a home-made LabVIEW 2011 software application (National instruments, Austin, TX, USA). 


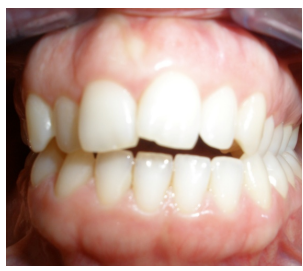

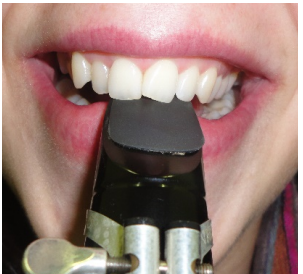

b

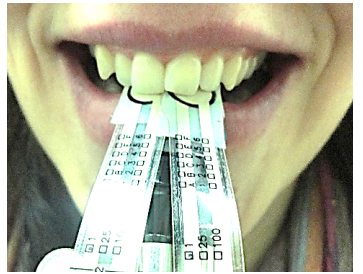

c

Fig. 1. Clarinetist's intra-oral frontal view in maximum intercuspation - anterior open bite (a); Embouchure position (b); FSR sensors adapted to the mouthpiece (c);

Brass Player: Infrared thermal imaging (IRT) was applied to the brass player (Fig. 2) following the procedures define by the "Glamorgan Protocol" [7]. The images were captured in an environment controlled room, with average temperature of $22{ }^{\circ} \mathrm{C}$, relative humidity $<50 \%$, absence of air flow and incident lightning over the subject. The equipment used was an uncooled thermal camera FLIR (Wilsonville, Oregon, USA) E60, operating in the long-range infrared spectrum $(7.5$ to $13 \mu \mathrm{m})$, with a focal plane array size of 320x240, a Noise Equivalent Temperature Difference (NETD) $<50 \mathrm{mK}$ at $30{ }^{\circ} \mathrm{C}$ and measurement accuracy of $\pm 2 \%$ of the overall reading. The camera was switched on 15 minutes before the image capture to avoid start-up drifting, the emissivity value was set to 0.98 and the rainbow false color scale was chosen the define the display colors. The subject was asked to avoid any heavy meal, alcohol intake, smoking, vasomotor drugs, physical activity or physiotherapy two hours before examination. At the appointment, the instrumentalist present himself shaved and without having any oil or ointment over the face skin. Before the images were taken, he acclimatized to the room conditions for a minimum of 10 minutes. The images of the head were taken at the lateral views, with the region of interest occupying $2 / 3$ of the image.
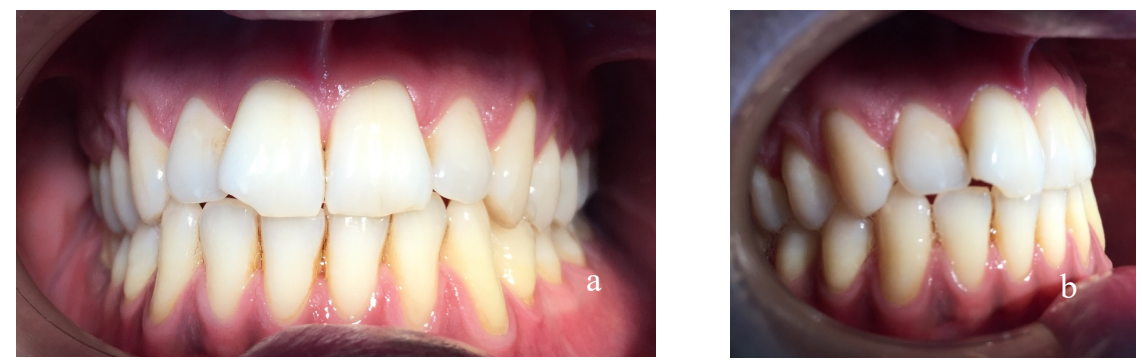

Fig. 2. Brass player's intra-oral frontal view in maximum intercuspation(a); Brass player's intra-oral right lateral view in maximum intercuspation - rotation of upper central incisor - tooth 11 (b); 
The infrared images were analyzed using the software package FLIR (Wilsonville, Oregon, USA) ThermaCAM Researcher Pro 2.10, three regions of interest (ROIs) were defined (Fig. 3), a rectangle for the anterior part of the right temporal muscle, a big circle for the masseter muscles and a small circle for the temporomandibular joint.
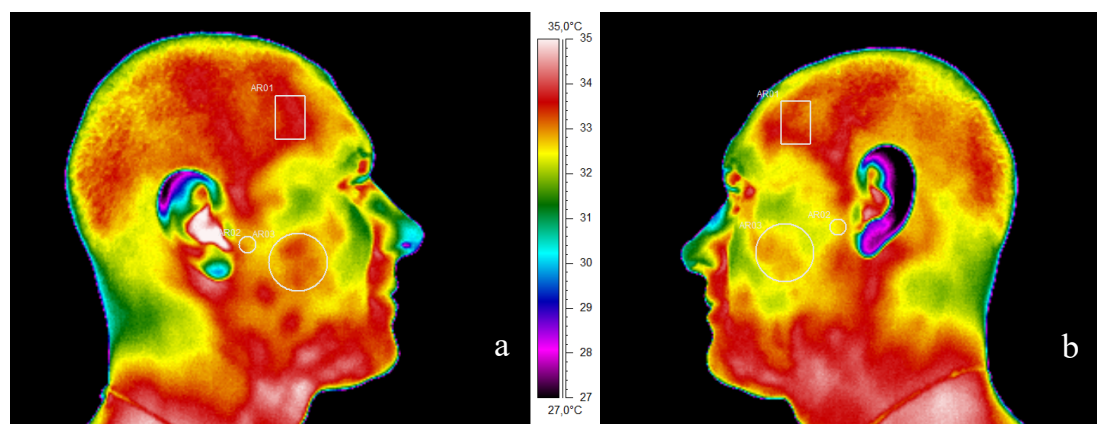

Fig. 3. Right lateral thermogram of the cranio-cervico-mandibular complex (CCMC) of the brass player. Regions of interest marked: anterior part of the right temporal muscle, right masseter muscle and right temporomandibular joint (a); anterior part of the left lateral thermogram of the $\mathrm{CCMC}$ ) of the brass player. Regions of interest marked: anterior part of the left temporal muscle, left masseter muscle and left temporomandibular joint (b).

Bassom Player: Lateral cephalograms were taken to the bassoon player (Fig. 4) in two situations, in maximum intercuspation and with the double reed mouthpiece inside the oral cavity, in order to determine the relationship between the different planes, angles and landmarks of the Ricketts analysis.

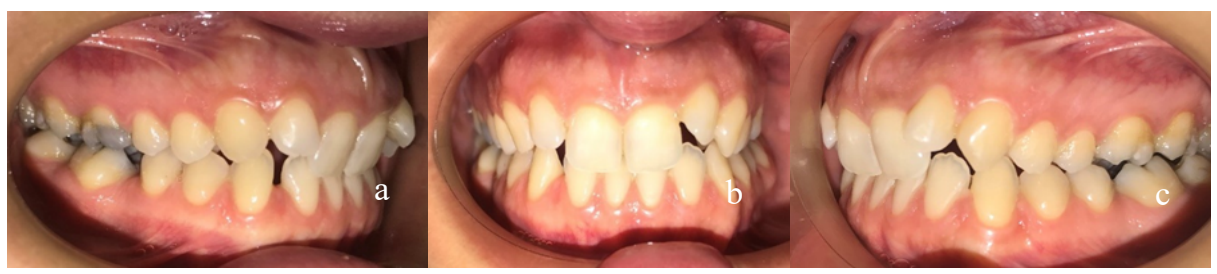

Fig. 4. Bassoons player's intra-oral right lateral (a), frontal (b) and left view (c) in maximum intercuspation. Lower incisors and upper central incisors are retroclined.

\section{$3 \quad$ Results and Discussion}

\subsection{Clarinet player FSR sensors analysis}

The FSR sensors allow clinicians, researchers and performers to determine the region of the upper central incisors that exerts more force in the single reed instrument player, or even quantify the existing forces applied on the lower lip that is retruded 
over the mandibular incisors [8]. If considered that the grip of the embouchure is established between these structures, it is interesting to highlight the influence of a malocclusion with mandibular or maxillary incisors more proclined or retroclined, tooth rotation, anterior crowding or even orthodontic braces on the embouchure. The occurrence of any of these situations will lead the single reed instrumentalist to adapt the mouthpiece at his/her convenience in order to be able to play. Since the prevalence of a malocclusion is high in the general population [9], it is probable that musicians will have the natural tendency of applying more force on one specific teeth. This will allow the single reed instrument to have the perfect embouchure that achieve all these conditionings of the orofacial tissues.

The Figure 5 represents the FSR output from the force applied by the upper central incisors, tooth 11 and 21, to the mouthpiece. The force was measured while playing a musical piece in a high pitch.

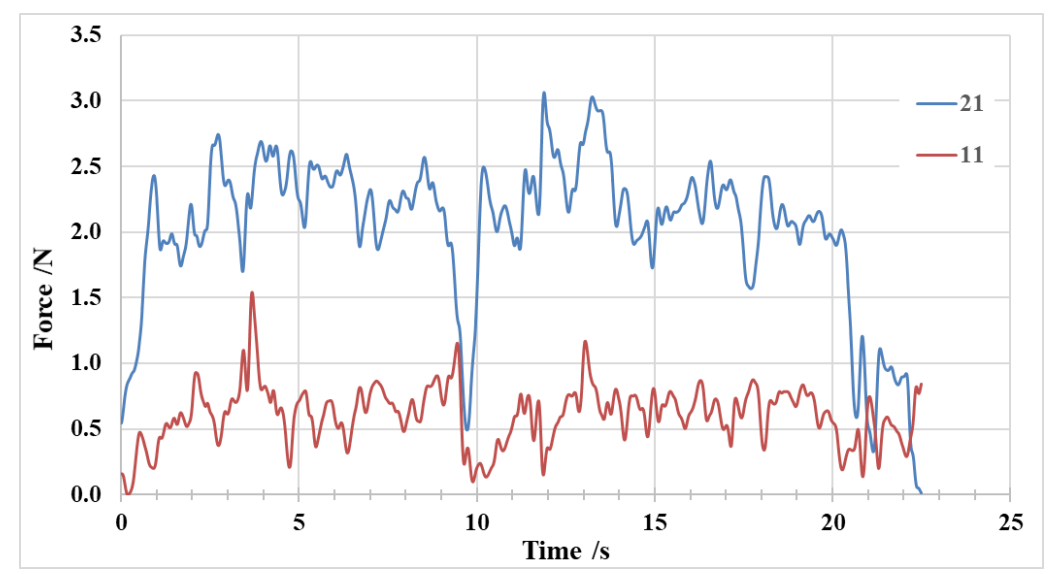

Fig. 5. Mouthpiece contact force of the clarinetist during the performance, tooth 11 and 21.

The expression - perfect embouchure - is extremely difficult to describe and define. There are many clinical features and anatomical characteristics that should be taken in consideration when analyzing this issue. If we think that the masticatory muscles of the stomatognathic apparatus has as primary functions: mastication, swallowing and speech, and as secondary functions: breathing and expression of emotions, it can make sense to include the act of playing a wind instrument as a parafunctional habit. Nevertheless, wind instrumentalists are taught to perform during long periods of time, eventually reaching a point of discomfort, or pain in certain regions of the craniocervico-mandibular complex (CCMC) [10]. The main reasons for this, is the overuse of specific muscles, excessive time of practice, high pressure being applied to the mouthpiece, inadequate postures adopted by the mandible and as a consequence the temporomandibular joint is subject to an excessive load [11].

The clarinet player involved in this research had an anterior open bite being more pronounced on the left side the maxilla, which will induce a deviation of the mouthpiece in a special direction added to the fact that the two upper central incisors are 
also misaligned. The musician normally seeks a contact point with the central incisor that has a more regular and straight incisal edge, which in this particular case doesn't happen. This clarinet player exerts more pressure in tooth $21(2.5 \mathrm{~N})$, which may occur probably because the embouchure mechanism does not only depend on the wind instrumentalist's teeth, but of anatomical structures like the temporomandibular joint and the masticatory muscles which will contribute for the stabilization of the mouthpiece within the oral cavity. Regarding this assumption, the player performed the stabilization of the mouthpiece against the tooth 21 and 22 which makes the kinematics of the mandible more favorable.

In relation to the lower jaw, the mouthpiece may also be deviated in case of any discomfort or pain eventually induced, for example, by tooth crowding against the lower lip. Likewise, there can also be an adaptation of the mouthpiece towards one particular side of the midline of the face. When these issues are analyzed in older musicians, e.g. at the age of 35 years, there are less possibilities to reprogram the embouchure, as a specific neuromuscular pattern has already been established.

These are orofacial issues that are being highlighted regarding the embouchure of professional musicians that have reached the highest level of their careers, playing in orchestras or giving lessons as musical teachers. The adjustment of the mouthpiece can be a stressful episode for the single reed instrument player, as the musician by himself doesn't recognize the dentist as an eminent person to change a musician's embouchure if needed when attending a dental appointment. After all, what does a dentist understand about a mouthpiece, or playing a clarinet if in the past years a teacher has spent a huge amount of time to define a perfect embouchure. Nevertheless, the importance that performing arts starts to have within the dental community or even within the wind instrumentalists' population is directly proportional to the more we learn with the orofacial issues of these musicians and therefore be able to help them.

The significance of this data is to provide dentists the capacity to understand vital matters of wind instrumentalists' basic mechanisms associated with the embouchure, and thus be able to help them to minimize orofacial pain related with his/her activity.

The idea of comprehending this phenomenon is not to tell the single reed instrument player that in the case of having orofacial pain after playing the clarinet, the tuba or the bassoon they should "try to play another instrument, like piano for example". The central point is that in order to have a perfect embouchure from a clinical and performing point of view, it is necessary for the parents of wind instrumentalists to take their children at the age of 10-12 years to a dentist to observe and analyze any of the above mentioned anatomical characteristics. A preventive approach towards understanding the musicians' embouchure can eventually lead to a "the perfect embouchure".

\subsection{Brass player infrared thermography analysis}

Based on the ROIs previously defined, it was measured the average temperature in each area Table 1, as well as, calculated the thermal asymmetry to the contralateral side, Fig. 6. 
Table 1. Thermographic analysis of the regions of interest of the brass player

\begin{tabular}{|l|c|c|c|}
\hline \multicolumn{1}{|c|}{ ROI } & Right & Left & Asymmetry \\
\hline Anterior part of temporal muscle $\left({ }^{\circ} \mathrm{C}\right)$ & 33.6 & 33.3 & 0.3 \\
\hline TMJ $\left({ }^{\circ} \mathrm{C}\right)$ & 32.9 & 32.6 & 0.3 \\
\hline Masseter muscle $\left({ }^{\circ} \mathrm{C}\right)$ & 33.0 & 32.6 & 0.4 \\
\hline
\end{tabular}

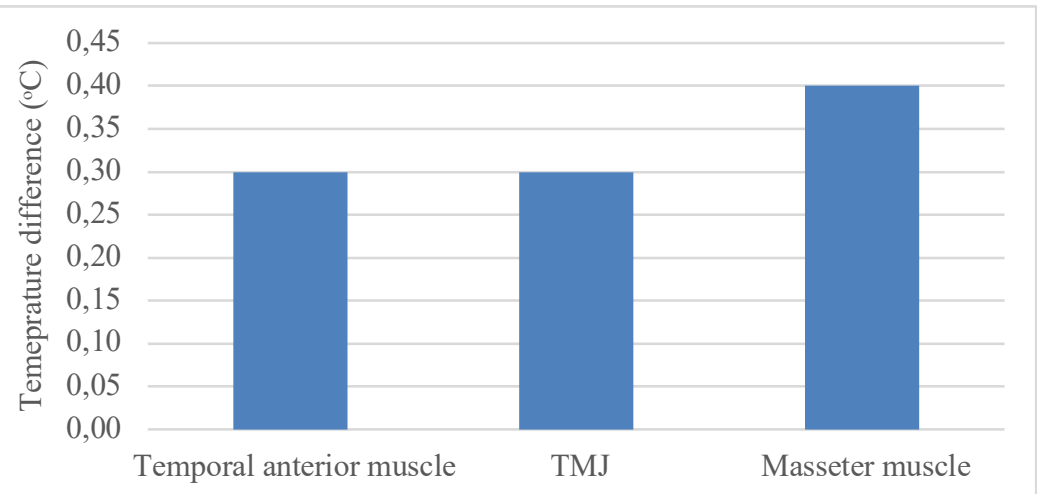

Fig. 6. Bar graph of the bilateral thermal asymmetry found in the respective regions of interest

Taking in comparison a tuba player with the type of occlusion of the single reed instrumentalist that is presented in this article, we could certainly observe a higher difficulty to adapt the mouthpiece of the instrument, since the lips of a tuba player have to perform an "optimal" sealing in order to blow the air to produce sound [12]. The brass instrument player would have the contact point of the mouthpiece against a sub-nasal point and the chin, due to the big dimension of the mouthpiece, while the lower lip is expected to vibrate against the upper lip and produce the different registrations. The protrusion of the upper incisors could eventually oblige the wind instrumentalist to provide a flexion of the cervical region with the inherent changes of the head posture in order to align the protruded upper teeth at more vertical position with a more favorable relationship to the lower incisors. Likewise, there would be an adaptation of certain regions of the CCMC in order to fulfil the necessary criteria to stabilize the mouthpiece and perform the perfect embouchure. Therefore, considering the anterior open bite of the clarinet player (Figure 1a) it was possible to observe the adaptation of the mouthpiece to the wind instrument player's occlusion. On the other hand, it could be questioned if this malocclusion had been provoked by the years of practice of the clarinet. To be accurate we don't know, what we know is FSR sensors can be a useful tool in order to quantify the contact pressures during the embouchure, complemented by the lateral cephalograms and a clinical observation of the contact point of the embouchure on different wind instruments. With this information it is possible to determine a pattern on the hypothetic influence of the mouthpiece in tooth position. Nevertheless, for this to occur, it would be necessary to implement longitudinal studies with wind instrumentalists following them since the age they chose their instrument, evaluating their occlusion, follow them till the adult age, and compare them with a control group. This prospective trial would be the efficient method to analyze the relation of 
the orofacial structures with the embouchure, and the eventual influence on the occlusion.

Currently, what we are heading for, is to provide the scientific community of different techniques and methods to complement our knowledge and understand more about the mechanism of a perfect embouchure.

In this particular case, the thermography was used in the region of the CCMC of the tuba player which showed an asymmetry of $0.4{ }^{\circ} \mathrm{C}$ on the masseter muscle. The highest temperature was present on the masseter of the right side which in our opinion is in accordance to the anatomical characteristics of the upper central incisors and the inherent implications of the teeth on the TMJ biomechanics during the embouchure, as well as the masticatory muscles. What this really means is that the tooth 11 appears to be rotated with the vestibular surface being slighted turned to the second quadrant, so when the tuba player is leaning his mouthpiece on the orofacial structures he will try to stabilize the mouthpiece towards a more regular surface. This area usually corresponds to the midline as a reference in order to adapt the mouthpiece correctly. But what is really happening is that the mouthpiece is placed against the surface of the tooth 21 and turned slighted to the left side, since the upper right central incisor is rotated. This rotation of the tooth 11 obligates the protrusion of the mandible with a slight deviation to the left side in order to allow the alignment of the upper and lower incisors when performing the embouchure and musical performance. This movement will originate a higher activity of the right masseter fibers that act as a protruding muscle besides of being a strong elevator muscle [13]. From a musical point of view, playing a high or a low note implicates the achievement of a stronger or looser aperture of the lip. Nevertheless, from a dentistry point of view what happens is a major or minor protrusion of the mandible. According to the repertoire and the occlusion of the brass player, there will be a larger movement of the mandible, directly related to the rotation/translation of the temporomandibular joint and activity of the masticatory muscles. Therefore, the tuba player, in order to achieve the perfect embouchure, executes an asymmetrical pattern of the condylar path, which will originate a higher activity of the right masseter muscle that is confirmed by the thermal images. In our opinion, the origin of the pain presented by the tuba player is related with the rotation of the upper central incisor which will promote an unbalanced activity of the muscles.

The results obtained with infrared thermography are in line with the diagnostic values used by Gratt et al. [14] and Haddad et al. [3], which emphasizes the importance of using this complementary diagnostic method that does not require contact with the patient, being fast, costless and safe. The method also showed good reliability and the information provided can be emphasized by using functional IRT [15].

\subsection{Bassoon player lateral cephalogram analysis}

Two teleradiographies were obtained from the bassoon player, one in maximum intercuspation, the other while performing the embouchure (Fig. 7). Taking into consideration this exam and the Ricketts analysis of the bassoon player in maximum intercuspation, one can conclude that both, upper and lower maxilla, are orthopositioned. The patient has a tendency to the dolichofacial facial type (long and narrow face) and 
the positive angle's convexity shows a prominent maxillary base compared to mandible (retrognathic profile). Regarding the upper and lower central incisors, both appeared to be retroclined. The results of the Ricketts analysis are indicated on Table 2 , [16].
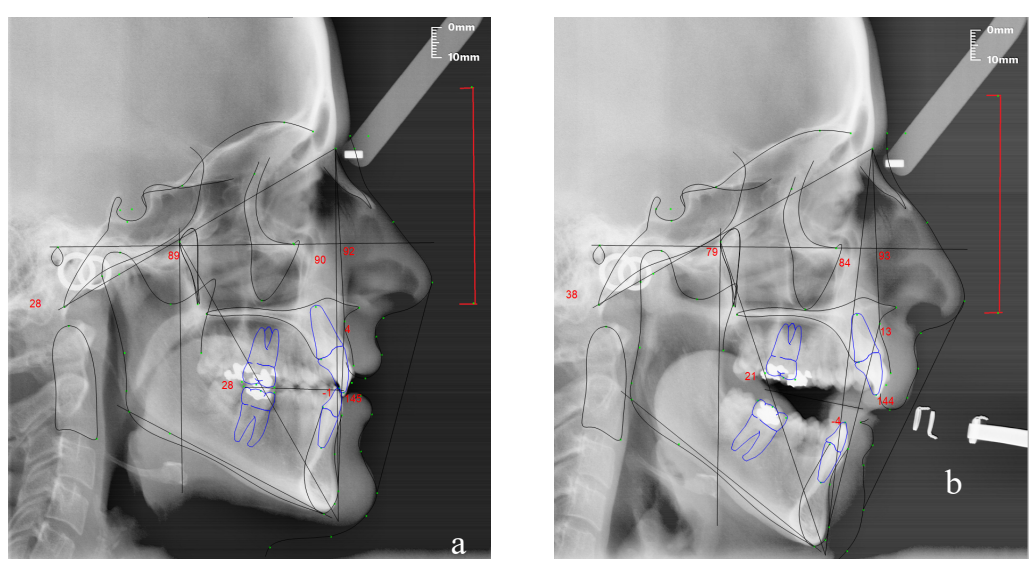

Fig. 7. Cephalometric analysis of the bassoon player in maximum intercuspation (a), and performing the embouchure (b)

Table 2. Cephalometric analysis results of the bassoon player in maximum intercuspidation. The symbol $(*)$ represents the deviation from the standard refence values. The more $\left(^{*}\right)$, the larger discrepancy to the normal standard (Dev Normal).

\begin{tabular}{|c|c|c|c|c|}
\hline Parameters & Measured & Normal & Std Dev & Dev Norm \\
\hline \multicolumn{5}{|c|}{ Craniofacial relation-Cranial structure } \\
\hline Cranial Length $(\mathrm{mm})$ & 84.2 & 30.1 & 2.5 & $9.6 * * * * * *$ \\
\hline Posterior Facial Height (Go-CF) (mm) & 80.3 & 54.8 & 3.3 & $7.7 * * * * * *$ \\
\hline Cranial Deflection $\left({ }^{\circ}\right)$ & 29.5 & 27.3 & 3.0 & 0.7 \\
\hline Porion Position (mm) & -56.5 & -38.6 & 2.2 & $-8.1 * * * * * *$ \\
\hline Ramus Position $\left({ }^{\circ}\right)$ & 81.7 & 76.0 & 3.0 & $1.9^{*}$ \\
\hline \multicolumn{5}{|c|}{ Craniofacial relation - Mx Position } \\
\hline Maxillary Depth (FH-NA) $\left(^{\circ}\right)$ & 92.3 & 90.0 & 3.0 & 0.8 \\
\hline Maxillary Height $(\mathrm{N}-\mathrm{CF}-\mathrm{A})\left({ }^{\circ}\right)$ & 56.4 & 55.6 & 3.0 & 0.3 \\
\hline Sn-Palatal Plane $\left(^{\circ}\right)$ & 14.1 & 7.3 & 3.5 & $2.0 * *$ \\
\hline \multicolumn{5}{|c|}{ Craniofacial relation - Md Positon } \\
\hline Facial Angle (FH-NPo) $\left(^{\circ}\right)$ & 89.8 & 88.6 & 3.0 & 0.4 \\
\hline Facial Axis-Ricketts (NaBa-PtGn) $\left(^{\circ}\right)$ & 89.5 & 90.0 & 3.5 & -0.2 \\
\hline FMA (MP-FH) $\left(^{\circ}\right)$ & 28.3 & 23.9 & 4.5 & $1.0^{*}$ \\
\hline Total Face Height $(\mathrm{NaBa}-\mathrm{PmXi})\left(^{\circ}\right)$ & 61.1 & 60.0 & 3.0 & 0.4 \\
\hline Facial Taper $\left(^{\circ}\right)$ & 61.9 & 68.0 & 3.5 & -1.7 \\
\hline \multicolumn{5}{|c|}{ Maxillo-Mandibular Relationships } \\
\hline Convexity (A-Npo)(mm) & 3.5 & 0.7 & 2.0 & $1.4^{*}$ \\
\hline Corpus Length (Go-Gn)(mm) & 108.6 & 75.2 & 4.4 & $7.6^{* * * * * * *}$ \\
\hline Mandibular Arc $\left(^{\circ}\right)$ & 34.2 & 30.2 & 4.0 & $1.0^{*}$ \\
\hline Lower Face Height (ANS-Xi-Pm) $\left(^{\circ}\right)$ & 48.2 & 45.0 & 4.0 & 0.8 \\
\hline \multicolumn{5}{|c|}{ Dental Relationships - Mx Dentition } \\
\hline
\end{tabular}


Paper-The Functional Interdependence of Wind Instrumentalists' Embouchure and Their Craniofacial ..

\begin{tabular}{|c|c|c|c|c|}
\hline U-Incisor Protrusion (U1-Apo) (mm) & 0.8 & 3.5 & 2.3 & $-1.2 *$ \\
\hline $\mathrm{U} 1-\mathrm{FH}\left({ }^{\circ}\right)$ & 107.4 & 111.0 & 6.0 & -0.6 \\
\hline U-Incisor Inclination (U1-Apo) $\left(^{\circ}\right)$ & 20.2 & 28.0 & 4.0 & $-2.0 * *$ \\
\hline U6 - PT Vertical (mm) & 28.1 & 18.0 & 3.0 & $3.4 * * *$ \\
\hline \multicolumn{5}{|c|}{ Dental Relationships - Md Dentition } \\
\hline L1-Incisor Protrusion (L1-Apo) (mm) & -1.4 & 2.0 & 2.3 & $-1.5^{*}$ \\
\hline L1 to A-Po $\left({ }^{\circ}\right)$ & 14.7 & 22.0 & 4.0 & $-1.8^{*}$ \\
\hline Mand Incisor Extrusion (mm) & 1.0 & 1.2 & 2.0 & -0.1 \\
\hline Hinge Axis Angle & 78.4 & 90.0 & 4.0 & -2.9 \\
\hline \multicolumn{5}{|c|}{ Dental Relations $M x / M d$ Dentition } \\
\hline Interincisal Angle (U1-L1) $\left(^{\circ}\right)$ & 145.1 & 130.0 & 6.0 & $2.5^{* *}$ \\
\hline Molar Relation (mm) & -0.9 & -3.0 & 1.0 & $2.1 * *$ \\
\hline Overjet (mm) & 2.2 & 2.5 & 2.5 & -0.1 \\
\hline Overbite $(\mathrm{mm})$ & 2.0 & 2.5 & 2.0 & 0.2 \\
\hline Occlusal Plane to $\mathrm{FH}\left({ }^{\circ}\right)$ & 2.5 & 6.8 & 5.0 & -0.9 \\
\hline \multicolumn{5}{|c|}{ Esthetic } \\
\hline Lower Lip to E-Plane (mm) & 11.6 & -2.0 & 2.0 & $-4.8 * * * *$ \\
\hline
\end{tabular}

By observing the second lateral teleradiography performing the gesture of embouchure (Fig. 7b), it is possible to notice a greater increase of the lower facial high and approximately $10^{\circ}$ posterior rotation of the mandible with rotational axis at the Xi point (center of mandible ramus). Interestingly, even with the small dimension of the bassoon's mouthpiece, the lower face height increased substantially comparing to the lateral teleradiography in maximum intercuspation. The long axis of the mouthpiece together with the anterior dental relationships (long axis of upper and lower central incisors) may determine the mouth opening pattern during the embouchure gesture. Likewise, a deep bite, crossed bite and/or open bite can promote a different mouthpiece insertion. Regarding the position of the condyle, the articular disc on the mandibular fossa and its biomechanics it is interesting to notice that hypothetically, when the wind instrumentalists adopt an instable position of the condyle articular disc complex in the temporal fossa for long periods of time during musical performance, he can be more predisposed to have TMJ discomfort/pain, or even to develop an internal derangement of the TMJ. A third parameter that can be analyzed, is the craniocervical angle. The cranio-cervical posture of this bassoon player seems to change from a normal up-right straight position to the adoption of a slightly anterior head position when performing the embouchure.

There are few studies associating the practice of a wind instrument to a possible malocclusion [17-20]. It is possible that a wind instrument will not affect a skeletal malocclusion, because it is at an earlier age that individuals' patterns are greater susceptible to acquire harmful habits. Playing a wind instrument professionally demands numerous daily hours of practice and therefore may result in tooth malposition, particularly on the anterior zone. Cephalometric studies of wind instrumentalists involving larger samples can be very important.

Malocclusion is related to the growth and development of the upper and lower jaws regarding the skeletal pattern, or an incorrect relationship of the upper and lower teeth which can be associated to harmful habits during childhood. Moimaz et al., in a longitudinal study of a baby population with 12 to 30 months concluded that early sucking 
habits and nocturnal mouth breathing were a predisposing habit to malocclusion. It was considered as harmful habits pacifier sucking, finger sucking, nocturnal mouth breathing, bottle feeding and breastfeeding, where this habits would influence the prevalence of overjet, open bite or posterior crossbite [21]. Similar results can be found in literature from other authors like Katz, Gimenez and Mocellin [22-24].

Lapatki et al. suggested that intrusion of the maxillary incisors should be part of the treatment of Class II, Division 2 cases to eliminate the non-physiologically high pressure exerted by the lower lip on these teeth and consequently, to reduce the high risk of a post-orthodontic relapse [25]. Additionally, Ingervall et al. in a study of 24 boys and 40 girls aged from 9 to 15 years old concluded that the lip bumper therapy was not effective on decreasing the pressure the lower lip exert on the lower incisors. Thus, no adaptation of the lower lip to the proclination occurred. After relapse of the proinclination the pressure from the lip would decreased to a value no different from that before the start of the treatment [26].

In prosthodontics there's a well described concept called neutral zone. Beresin and Schiesser suggested in 1976 that the denture teeth should be arrange in this neutral zone that is a specific area where the function of the musculature will not unseat the denture and where forces generated by the tongue will be neutralized by the forces generated by the lips and cheeks [27]. The celebrity quote "The function makes the organ" by Jean Baptiste Lamark captures the fact that organisms can provide their offspring with some characteristics acquired during lifetime resulting in the species' gradual adaptation to the environment. For a correct embouchure mechanism of a bassoon, it is required the lips to be retruded over the teeth, and the jaw should be pulled back just enough to create a slight overbite [28]. The present cephalometric analysis showed that both maxillary and mandibular incisors were in a retroclined position. The upper incisor had $20.2^{\circ}$ (value expected: $28 \pm 4^{\circ}$ ) and the lower incisor had $14.7^{\circ}$ (value expected: $22 \pm 4^{\circ}$ ). Thus, confirming the possible effect of a present hyperactivity of the upper and lower lip. Furthermore, an inexperienced bassoon player or with a deficient breath-leading skills will over-depend of the embouchure and will have a tighter embouchure. For a more relaxed embouchure, to allow the jaw opening and to maximize the resonance, a better abdominal support is needed [29].

The lateral cephalograms can be an important tool on the analyses of the interface between the mouthpiece of any wind instrumentalist and the orofacial structures. In this article it can be observed in the lateral cephalogram of a bassoon player the upper and lower lip are retruded over the respective central incisors. The angle of insertion of the bassoon's player mouthpiece inside the oral cavity is almost parallel to the Frankfurt plan, making an angle of $70^{\circ}$ with the upper incisal plan. If it is taken into consideration that both, upper and lower lips are retruded over the respective incisors edge, this obliges a mouth opening in accordance to the position adopted by the lips during the embouchure.

Therefore analyzing the different type of mouthpieces and their interrelationship with the mandibular kinematics during the embouchure, it is possible to mention that in this case the amount of mouth opening is associated to the retroclination of the upper and lower incisors and the consequent retrusion of the lips over the respective teeth, while the single reed instrument player, the clarinetist, has to insert his/her 
mouthpiece inside the mouth at a more vertical position than, for example, the saxophone player, whilst the brass instrument players will have to lean the mouthpiece against the lips and the protrusion of the mandible during the embouchure can also be related to the position of the upper central incisors.

A tuba player that has a Class II div 2, independently of not having to introduce his mouthpiece inside the mouth to perform the embouchure, will always need to have the upper central incisors aligned with the lower central incisors for the air flow to pass and produce a sound. While in the case of a clarinet player with an occlusion Class II $\operatorname{div} 2$, there would always be the need to retruded the lower lip over the lower central incisors and place the mouthpiece at a "more" vertical position. Regardless to the type of occlusion of the clarinet player, the mouth opening of this wind instrumentalist will always demand the retrusion of the lower lip and the subsequent inclination of the mouthpiece inside the oral cavity. When performing the embouchure, the major difference will be related to the biomechanics of the temporomandibular joint since the clarinet player with, for example, an occlusion Class III, will have to have a bigger opening of the mouth when comparing to a brass instrument with the same type of occlusion, with the difference that when playing a high note, the embouchure of the clarinet player obliges a retrusion of the mandible with the mouth slightly more open than the brass instrument. Theoretically a brass instrumentalist with the same type of occlusion of a clarinet player and when comparing their embouchure mechanism, the brass instrumentalist will move the mandible backwards and forwards at a more stable position comparing to the single reed instrument player that has the condyles at a more instable position, since these can be more advanced on the mandibular fossa against the slope of the eminence due to the mouth opening for the insertion of the mouthpiece inside the oral cavity.

Apparently the embouchure of these wind instrumentalists occurs in a natural way and the above mentioned anatomical areas do not seem to make part of a major concern on their performance, since they were used to adapt the mouthpiece and execute their own perfect embouchure. From a clinical and dental point of view, this perfect embouchure can exist until the day the musician is absent of pain on the masticatory muscles, on the temporomandibular joint and the teeth. If any disequilibrium happens in any of these structures, the perfect embouchure will be compromised. The physiological tolerance and resistance of each individual differs and it is important that a dentist can identify these issues and correlate the clinical point of view with the necessities of the wind instrumentalist's embouchure.

Therefore, a thoroughly examination of the CCMC is important since the young age, when they start playing. Eventually, at this stage the instrument can be changed in order to be more suitable to the type of occlusion of the individual. In any case, the analysis of the musician based on CAMIST technique for temporomandibular disorders in performing arts medicine may be helpful to minimize oral pain [30]. 


\section{Conclusion}

There is a perfect embouchure from a clinical point of view regarding the dental features and specific orofacial structures of each wind instrument player. Nevertheless, the classic centered embouchure with equal pressures being distributed symmetrically on the mouthpiece that usually renewed pedagogues and musical teachers try to implement in their students is more difficult to achieve. Understanding the anatomic limitations and implications on the final outcome of the "centered embouchure" is fundamental to analyze and treat a wind instrumentalist within a dental appointment.

The implementation of different techniques such as FSR sensors, infrared thermography and lateral cephalograms in the analysis of wind instrumentalists can be considered as a complementary diagnostic tool in order to comprehend and quantify the physiological occurrences during the embouchure.

The dentistry field is one of the most important areas for wind instrument players. Likewise, the most exhaustive comprehension that is possible to obtain regarding different regions of interest of the CCMC the more knowledge we have regarding the embouchure mechanisms.

This information should be shared within wind instrumentalists, musical teachers, oral health professionals in order to follow the wind instruments students since the age they start playing, to be able to treat dento-maxilla discrepancies, teeth rotations, orofacial pain, temporomandibular disorders or any comorbid situations that can have direct implications on the wind instrumentalists "perfect embouchure".

\section{Acknowledgement}

The authors gratefully acknowledge the funding of project LAETA UID/EMS/50022/2013.

\section{References}

[1] Ring, F. (2015). Infrared Imaging; A casebook in clinical medicine. Infrared Imaging; A casebook in clinical medicine, by Ring, Francis. ISBN: 978-0-7503-1143-4. IOP ebooks. Bristol, UK: IOP Publishing, 2015.

[2] Ring, E. F. J., \& Ammer, K. (2012). Infrared thermal imaging in medicine. Physiological measurement, 33(3), R33. https://doi.org/10.1088/0967-3334/33/3/r33

[3] Haddad, D. S., Brioschi, M. L., Vardasca, R., Weber, M., Crosato, E. M., \& Arita, E. S. (2014). Thermographic characterization of masticatory muscle regions in volunteers with and without myogenous temporomandibular disorder: preliminary results. Dentomaxillofacial Radiology, 43(8), 20130440. https://doi.org/10.1259/dmfr.20130440

[4] Haddad, D. S., Brioschi, M. L., \& Arita, E. S. (2012). Thermographic and clinical correlation of myofascial trigger points in the masticatory muscles. Dentomaxillofacial Radiology, 41(8), 621-629. https://doi.org/10.1259/dmfr/98504520

[5] Biagioni, P. A., Longmore, R. B., McGimpsey, J. G., \& Lamey, P. J. (1996). Infrared thermography. Its role in dental research with particular reference to craniomandibular dis- 
orders. Dentomaxillofacial Radiology, 25(3), 119-124. https://doi.org/10.1259/dmfr.25.3. $\underline{9084259}$

[6] Canavan, D., \& Gratt, B. M. (1995). Electronic thermography for the assessment of mild and moderate temporomandibular joint dysfunction. Oral Surgery, Oral Medicine, Oral Pathology, Oral Radiology, and Endodontology, 79(6), 778-786. https://doi.org/10.1016/s 1079-2104(05)80316-6

[7] K. Ammer. (2013). The Glamorgan Protocol for recording and evaluation of thermal images of the human body, Thermol Int. 2008, 18(4): 125-129.

[8] Clemente, M. P., Moreira, A., Mendes, J., Ferreira, A. P., \& Amarante, J. M. (2019). Wind Instrumentalist Embouchure and the Applied Forces on the Perioral Structures. The Open Dentistry Journal, 13(1). https://doi.org/10.2174/1874210601913010107

[9] Bauman, J. M., Souza, J. G. S., Bauman, C. D., \& Flório, F. M. (2018). Epidemiological pattern of malocclusion in Brazilian preschoolers. Ciencia \& saude coletiva, 23(11), 38613868. https://doi.org/10.1590/1413-812320182311.24722016

[10] Gasenzer, E. R., Klumpp, M. J., Pieper, D., \& Neugebauer, E. A. (2017). The prevalence of chronic pain in orchestra musicians. GMS German Medical Science, 15.

[11] Clemente, M., Mendes, J., Moreira, A., Vardasca, R., Ferreira, A., \& Amarante, J. (2018). Wind instrumentalists and Temporomandibular Disorder: From Diagnosis to Treatment. Dentistry journal, 6(3), 41. https://doi.org/10.3390/dj6030041

[12] Kim, J. S., An, J. Y., Lee, K. S., \& Kim, H. T. (2007). Cooling can relieve the difficulty of playing the tuba in a patient with embouchure dystonia. Movement disorders: official journal of the Movement Disorder Society, 22(15), 2291-2292. https://doi.org/10.1002/mds. $\underline{21737}$

[13] Michelotti, A., Rongo, R., Valentino, R., D’antò, V., Bucci, R., Danzi, G., \& Cioffi, I. (2018). Evaluation of masticatory muscle activity in patients with unilateral posterior crossbite before and after rapid maxillary expansion. European journal of orthodontics, 41(1), 46-53. https://doi.org/10.1093/ejo/cjy019

[14] Gratt, B. M., Graff-Radford, S. B., Shetty, V., Solberg, W. K., \& Sickles, E. A. (1996). A 6-year clinical assessment of electronic facial thermography. Dentomaxillofacial Radiology, 25(5), 247-255. https://doi.org/10.1259/dmfr.25.5.9161178

[15] Costa, A. C., Dibai Filho, A. V., Packer, A. C., \& Rodrigues-Bigaton, D. (2013). Intra and inter-rater reliability of infrared image analysis of masticatory and upper trapezius muscles in women with and without temporomandibular disorder. Brazilian journal of physical therapy, 17(1), 24-31. https://doi.org/10.1590/s1413-35552012005000058

[16] Joshi, M., Wu, L. P., Maharjan, S., \& Regmi, M. R. (2015). Sagittal lip positions in different skeletal malocclusions: a cephalometric analysis. Progress in orthodontics, 16(1), 8. https://doi.org/10.1186/s40510-015-0077-x

[17] Grammatopoulos, E., White, A. P., \& Dhopatkar, A. (2012). Effects of playing a wind instrument on the occlusion. American Journal of Orthodontics and Dentofacial Orthopedics, 141(2), 138-145. https://doi.org/10.1016/j.ajodo.2011.06.044

[18] Van der Weijden, F. N., Kuitert, R. B., Berkhout, F. R. U., \& van der Weijden, G. A. (2018). Influence of tooth position on wind instrumentalists' performance and embouchure comfort. Journal of Orofacial Orthopedics/Fortschritte der Kieferorthopädie, 79(3), 205218. https://doi.org/10.1007/s00056-018-0128-2

[19] Rindisbacher, T., Hirschi, U., Ingervall, B., \& Geering, A. (1990). Little influence on tooth position from playing a wind instrument. The Angle Orthodontist, 60(3), 223-228.

[20] Brattström, V., Odenrick, L., \& Kvam, E. (1989). Dentofacial morphology in children playing musical wind instruments: a longitudinal study. The European Journal of Orthodontics, 11(2), 179-185. https://doi.org/10.1093/oxfordjournals.ejo.a035981 
[21] Moimaz, S. A. S., Garbin, A. J. Í., Lima, A. M. C., Lolli, L. F., Saliba, O., \& Garbin, C. A. A. S. (2014). Longitudinal study of habits leading to malocclusion development in childhood. BMC Oral Health, 14(1), 96. https://doi.org/10.1186/1472-6831-14-96

[22] Gimenez, C. M. M., Moraes, A. B. A. D., Bertoz, A. P., Bertoz, F. A., \& Ambrosano, G. B. (2008). First childhood malocclusion s prevalence and its relation with breast feeding and oral habits. Revista Dental Press de Ortodontia e Ortopedia Facial, 13(2), 70-83. https://doi.org/10.1590/s1415-54192008000200009

[23] Katz, C. R. T., Rosenblatt, A., \& Gondim, P. P. C. (2004). Nonnutritive sucking habits in Brazilian children: effects on deciduous dentition and relationship with facial morphology. American Journal of Orthodontics and Dentofacial Orthopedics, 126(1), 53-57. https://doi.org/10.1016/j.ajodo.2003.06.011

[24] Mocellin M FE, Gavazzoni FB, Ataíde AL, Ouriques FL, Herrero Júnior F. (2000). Cephalometric-radiographic study and otolaryngology correlating the degree of nasal obstruction and the pattern of facial growth non treated orthodontic patients. Braz J Otorhinolaryngol, 66:116-20.

[25] Lapatki, B. G., Mager, A. S., Schulte-Moenting, J., \& Jonas, I. E. (2002). The importance of the level of the lip line and resting lip pressure in Class II, Division 2 malocclusion. Journal of dental research, 81(5), 323-328. https://doi.org/10.1177/154405910208100507

[26] Ingervall, B., \& Thüer, U. (1998). No effect of lip bumper therapy on the pressure from the lower lip on the lower incisors. The European Journal of Orthodontics, 20(5), 525-534. https://doi.org/10.1093/ejo/20.5.525

[27] Porwal, A., \& Sasaki, K. (2013). Current status of the neutral zone: a literature review. The Journal of prosthetic dentistry, 109(2), 129-134. https://doi.org/10.1016/s0022-3913(13)60 $\underline{030-\mathrm{x}}$

[28] Jooste, S. J. (1984). The Technique of Bassoon Playing: An Evaluative and Methodological Study. Departement Sentrale Publikasies, Potchefstroomse Universiteit vir CHO.

[29] Spencer, W., \& Mueller, F. (1969). The art of bassoon playing. Alfred Music.

[30] Clemente, M. P., Mendes, J. G., Vardasca, R., Ferreira, A. P., \& Amarante, J. M. (2018). Combined Acquisition Method of Image and Signal Technique (CAMIST) for assessment of temporomandibular disorders in performing arts medicine. Med Probl Perform Art, 33(3), 205-212. https://doi.org/10.21091/mppa.2018.3029

\section{Authors}

Miguel P. Clemente, miguelpaisclemente@hotmail.com - holds a PhD in Dental Medicine (2019), a Master Degree in Conservative Dental Medicine from Universidade do Porto, and a degree in Dental Medicine from Instituto Superior de Ciências da Saúde - Norte. He is currently invited professor at the Surgery and Physiology Department, Faculty de Medicine, member of the general Council of Dentists and Founder of the Portuguese Association of Medicine and Performing Arts.

José M. Amarante, amarante $@$ med.up.pt - hold a PhD in Surgery from the Faculdade de Medicina da Universidade do Porto, Portugal. He is full professor at the Faculdade de Medicina, head of Surgery and Physiology and member of the board of the Faculty as well as, member of the board of Labiomep - Biomechanics lab of the University of Porto.

André Moreira, Mimd12064@,fmd.up.pt - DMD, post-graduation student in prosthodontics, Faculty of Dental Medicine, University of Porto. Works as general dentist 
and prosthodontist. His scientific areas of interest are oral rehabilitation, temporomandibular disorders, sports dentistry and facial thermography.

Afonso P. Ferreira, aferreira@fmd.up.pt - holds a PhD in orthodontics from Universidade do Porto (1997) and a degree in dentistry in 1982. He is full professor at the Faculdade de Medicina Dentária from 2003, where he was also director of the board. In July 1982, he began to practice general dental medicine his own office located in the city of Póvoa de Varzim. He is a founding partner of the Portuguese Society of Dento-Facial Orthopedics, Specialist in Orthodontics by the Council of Dentists and was member of the Board of the College of Orthodontics. In the free time he enjoys painting and sculpture.

Ricardo Vardasca, ricardo.vardasca@fe.up.pt - holds a BSc (hons) in Information Technology and a PhD in Medical Informatics from the University of South Wales (UK) and a degree in Computer Science Engineering from the Instituto Politecnico de Leiria (Portugal). Actually, he is an integrated researcher at INEGI-LAETA and research fellow at the Faculdade de Engenharia da Universidade do Porto, Portugal, external professor at the Faculty of Medicine and Odontology of University of Valencia (Spain), visiting fellow at University of South Wales (UK) and visiting researcher at University of Wollongong (Australia). He acts as general secretary of the European Association of Thermology and is a Fellow of the Royal Photographic Society.

Joaquim Mendes, jgabriel@fe.up.pt - holds a PhD in Industrial Electronics from School of Engineering - University of Minho (2003), a Master in Computer \& Industrial Engineering from Universidade do Porto, a Post-graduation in Automation and Management of Industrial Processes, and a degree in Mechanical Engineering. He is currently Associate Professor at Faculdade de Engenharia da Universidade do Porto (Portugal) and researcher at INEGI - Institute of Science and Innovation in Mechani$\mathrm{cal}$ and Industrial Engineering. He is member of the board of IEEE Instrumentation and Measurement Society - Portuguese chapter, and senior member of Mechanical Engineering Council.

Article submitted 2019-05-31. Resubmitted 2019-07-11. Final acceptance 2019-07-12. Final version published as submitted by the authors. 